Research Article

\title{
New Method to Design Coal Pillar for Lateral Roof Roadway Based on Mining-Induced Stress: A Case Study
}

\author{
Feng Wang $\mathbb{D}^{1,2}$ Shaojie Chen, ${ }^{1,2}$ Jialin $X u \mathbb{D}^{3}{ }^{3}$ and Mengzi Ren ${ }^{1}$ \\ ${ }^{1}$ State Key Laboratory of Mining Disaster Prevention and Control Co-Founded by Shandong Provence and \\ the Ministry of Science and Technology, Shandong University of Science and Technology, Qingdao 266590, China \\ ${ }^{2}$ College of Mining and Safety Engineering, Shandong University of Science and Technology, Qingdao 266590, China \\ ${ }^{3}$ State Key Laboratory of Coal Resources and Safe Mining, China University of Mining and Technology, Xuzhou, \\ Jiangsu 221116, China
}

Correspondence should be addressed to Feng Wang; wangfeng@sdust.edu.cn

Received 15 June 2018; Revised 28 September 2018; Accepted 3 October 2018; Published 24 October 2018

Academic Editor: Flavio Stochino

Copyright (c) 2018 Feng Wang et al. This is an open access article distributed under the Creative Commons Attribution License, which permits unrestricted use, distribution, and reproduction in any medium, provided the original work is properly cited.

The traditional method to design coal pillar for lateral roof roadway was established based on the mining-induced strata movement contour which is considered as a straight line, while ignoring the variations of the internal strata deformation law as well as stress distribution characteristics. In order to make up for this deficiency, in this study, evolution of mining-induced stress in the overlying strata was simulated using physical and numerical simulations, and a method to design coal pillar for lateral roof roadway based on mining-induced stress was proposed. The results indicate that the stress of the overlying strata is redistributed during excavation, and the stress distribution can be divided into a stress-relaxation area, a stress-concentration area, and an in situ stress area. The contour line of 1.05 times the in situ stress is used to define the mining-induced stress contour. Stress inside the contour is redistributed while outside the contour the overlying strata are still within the in situ stress area. Mining-induced stress contour presents a concave-upward type from coal seam to the overlying strata that cannot be merged into a straight one due to their different characteristics of movement and deformation. With this in mind, this study proposed a method to design the width of coal pillar for lateral roof roadway according to the mining-induced stress contour. According to mining-induced stress contour, the width of coal pillar for lateral roof roadway of longwall panel 31100 is $160 \mathrm{~m}$, and the maximum deformation of the roadway is $270 \mathrm{~mm}$. The new method can definitely meet engineering demands.

\section{Introduction}

Multiseam longwall coal mining is widely applied both here in China and abroad [1, 2], for example, Germany has a history of multiseam mining over the past 100 years. It is very common to mine multiple coal seams simultaneously due to the close distance coal seams. The roadway in the upper panel is located in the overlying strata of the lower coal seam, that is, lateral roof roadway. The lateral roof roadway influenced by the lower coal seam mining is prone to play an important role in transportation, ventilation, etc., during close distance coal seams repeat mining [3-5]. However, the multiseam longwall coal mining will lead to strata movement, stress redistribution, roof caving, and overburden fracturing, resulting in lateral roof roadway convergence. Nevertheless, the protection of lateral roof roadway requires the determination of the delimitation of the risk of collapse.

The traditional strata movement contour is foundation and precondition of the prediction of strata movement and deformation as well as the protection of roadway outside the mining area [6-9]. An appropriate coal pillar is designed based on the evolution of strata movement contour [10,11]. Traditionally, the strata movement contour is considered to be a straight line based on the mining-induced movement angle of the overlying strata $[6,12]$. According to the definition of the mining-induced movement angle, only one angle of the rock strata is used to represent the characteristics of 
overlying strata movement, while the internal deformation mechanism as well as the stress distribution of the overlying strata is ignored. Therefore, the lateral roof roadway would mostly be damaged as the coal pillar determined by the mining-induced movement angle of the rock strata was not appropriate. For example, based on a $61^{\circ}$ mining-induced movement angle [11], coal pillar in $90 \mathrm{~m}$ wide was reserved to protect the lateral roof roadway in Pingdingshan No. 1 coal mine, which makes it outside of the overlying strata movement area of longwall panel 31010. However, during the mining process, serious heave was still occurred in the roadway. This paper analyzed the deformation mechanism of the roadway based on the mining-induced stress and proposed a method to design coal pillar for lateral roof roadway. The contents are as follows:

(1) Deformation mechanism of the lateral roof roadway was studied by field measurements and numerical simulations.

(2) Distribution of mining-induced stress in the overlying strata was studied by theoretical analysis and numerical and physical simulation.

(3) The method was proposed to design coal pillar for the lateral roof roadway based on the mininginduced stress contour.

(4) According to the method, when the width of coal pillar was $150 \mathrm{~m}$, the maximum deformation of the roadway was $270 \mathrm{~mm}$, which ensured the normal usage of this roadway.

\section{Mechanism of Lateral Roof Roadway Failure}

2.1. Mining Conditions. As shown in Figure 1, Pingdingshan No. 1 Coal Mine is located in Pingdingshan, Henan Province, China. The average depth of the roadway studied in this paper is $470 \mathrm{~m}$, with a section size (width $\times$ height) of $4.2 \mathrm{~m} \times$ $3.0 \mathrm{~m}$. The lateral roof roadway is located in the overlying strata of the longwall panels 21210 and 31010 in \#10 coal seam. The width of panel 21210 and 31010 is $125 \mathrm{~m}$ and $180 \mathrm{~m}$ on average. The thickness of \#10 coal seam ranges from $2.1 \mathrm{~m}$ to $3.8 \mathrm{~m}$, and the inclination of the coal seam ranges from $4^{\circ}$ to $12^{\circ}$. The drilling columnar and lithological parameters of the roof are shown in Figure 1.

In order to avoid the influence of mining, coal pillar for lateral roof roadway was designed via the displacement angle of rock strata. According to the displacement angle of rock strata $\left(\beta=61^{\circ}\right)[11]$ in the coal mine, the location of the roof roadway was originally determined as shown in Figure 1. The average vertical distance between the roadway and the \#10 coal seam is $85 \mathrm{~m}$, and the width of the coal pillar on the side of panel 31010 is $90 \mathrm{~m}$. Before Oct 2011, the width of the coal pillar between panel 21210 and the roadway was gradually decreased. From Oct 2011, the width of the coal pillar between the panel and the roadway was maintained at $165 \mathrm{~m}$. Although coal pillar was reserved for the lateral roof roadway, severe deformations still occurred in partial positions of roadway during the mining period of panel 31010 .
2.2. Field Observation. Measuring points were installed to monitor deformation in the roadway at intervals of $50 \mathrm{~m}$ on Jan 21, 2012. After the points were arranged, horizontal convergence (rib-to-rib convergence) and vertical convergence (roof-to-floor convergence) of the lateral roof roadway were also monitored on Feb 12, 2012, Mar 10, 2012, Apr 06, 2012, Apr 30, 2012, Jun 09, 2012, and Jul 07, 2012, respectively.

As shown in Figure 2, after the mining of panel 21210, there is no horizontal and vertical convergence before the panel 31010 excavation, indicating that the mining of panel 21210 has almost no effect on the lateral roof roadway. During the mining of panel 31010 until July 2012, severe deformation occurred, so it is caused by panel 31010 excavation. The maximum horizontal convergence and vertical convergence were $488 \mathrm{~mm}$ and $587 \mathrm{~mm}$.

2.3. Numerical Simulation. $\mathrm{UDEC}^{2 \mathrm{D}}$ was used to study the deformation mechanism of the roadway. Section A-A in Figure 1 was selected to build the model with the dimensions of $1500 \mathrm{~m}$ wide and $300 \mathrm{~m}$ height shown in Figure 3. The hierarchies of the overlying strata were correspondingly simplified according to the field drilling columnar. Field measurement showed that the vertical stress was $14.67 \mathrm{MPa}$. The maximum principal stress was $17.44 \mathrm{MPa}$, and the minimum principal stress was $15.64 \mathrm{MPa}$. This in situ stress state was incorporated into the model. During the simulating process, the elastic-plastic model $[13,14]$ was applied to the model, which can represent shear failure in rock and is widely used in underground engineering. The mechanical properties of different rock layers are shown in Table 1 . Figure 3 shows that good agreement was achieved between the numerical results and the laboratory test for stress-strain curve of the silty mudstone sample.

Three plans were designed in this experiment: mining panel 31010; mining panel 21210; and mining both panels. Ten measuring lines separately located in the positions of $Y=$ $26 \mathrm{~m}, 66 \mathrm{~m}, 108 \mathrm{~m}, 166 \mathrm{~m}, 216 \mathrm{~m}, 266 \mathrm{~m}, 316 \mathrm{~m}, 366 \mathrm{~m}$, $416 \mathrm{~m}$, and $466 \mathrm{~m}$ were arranged in the coal seam and overlying strata to monitor the mining-induced stress.

In order to determine the influence distance of mininginduced stress, the curve formed by connecting the points, where the mining-induced stress is equal to 1.05 times the in situ stress $[15,16]$, is defined as mining-induced stress contour. Therefore, the stress inside the mining-induced stress contour is redistributed, while the outside strata are still located in the in situ stress zone. Mining-induced stress on the overlying strata is distributed as shown in Figure 4.

(1) After mining of panel 21210, there is no deformation because the roadway is located outside the mininginduced stress contour.

(2) After excavation of panel 31010, the width of the coal pillar in the roadway of panel 31010 is significantly smaller than that of panel 21210. Considering that the roadway is located inside the mining-induced stress contour, there are slight deformations of roadway. 


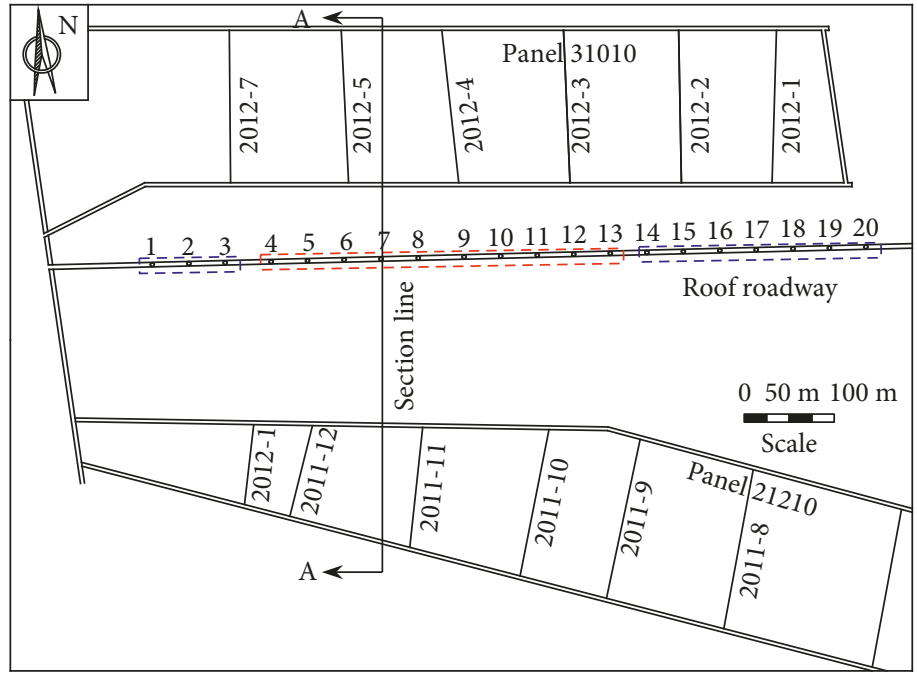

- Measuring point

2012-7 Location of panel

(a)

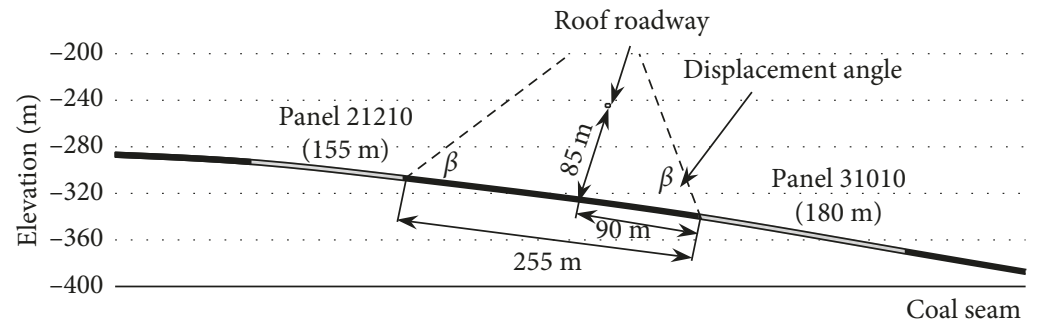

(b)

\begin{tabular}{|c|c|c|c|c|c|}
\hline No. & $\begin{array}{l}\text { Thickness } \\
\text { (m) }\end{array}$ & $\begin{array}{l}\text { Depth } \\
(\mathrm{m})\end{array}$ & Lithology & Remarks & Column \\
\hline 16 & 2.90 & 463.35 & Coal seam & & \\
\hline 15 & 10.90 & 474.25 & Silty mudstone & $\%$ & $\div$ - \\
\hline 14 & 1.45 & 475.70 & Coal seam & & 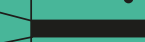 \\
\hline 13 & 1.75 & 477.45 & Siltstone & & $\bullet \bullet \bullet$ \\
\hline 12 & 0.25 & 477.70 & Coal seam & & - - - \\
\hline 11 & 1.10 & 478.80 & Siltstone & & $\therefore-\overline{-}$ \\
\hline 10 & 4.74 & 483.54 & Medium grained sandstone & & \\
\hline 9 & 12.86 & 496.40 & Silty mudstone & & $\overline{-} \div$ \\
\hline 8 & 0.55 & 496.95 & Coal seam & & - - - \\
\hline 7 & 22.05 & 519.00 & Silty mudstone & & $\therefore-\bar{\bullet}$ \\
\hline 6 & 21.82 & 540.82 & Medium grained sandstone & & $\bullet \quad \bullet$ \\
\hline 5 & 0.68 & 541.50 & Coal seam & & $\bullet \quad \cdots$ \\
\hline 4 & 2.45 & 543.95 & Silty mudstone & & $\bullet \bullet \bullet$ \\
\hline 3 & 1.55 & 545.50 & Coal seam & & $\ldots$ \\
\hline 2 & 3.95 & 549.45 & Mudstone & & \\
\hline 1 & 3.10 & 552.55 & \#10 coal seam & & \\
\hline
\end{tabular}

(c)

Figure 1: Layout sketch of longwall panel and lateral roof roadway: (a) location of longwall panel and lateral roof roadway; (b) profile of longwall panel and lateral roof roadway; (c) borehole columnar section of mining area. ※Location of the lateral roof roadway in our study. 


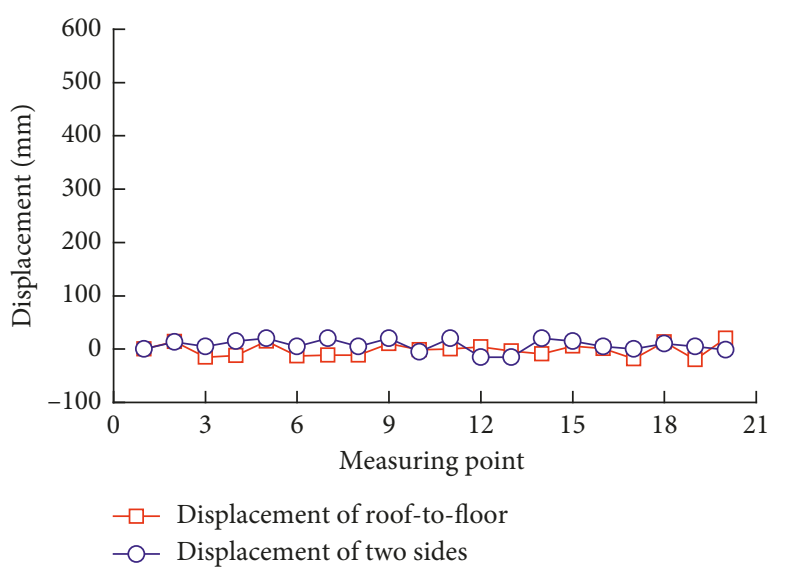

(a)

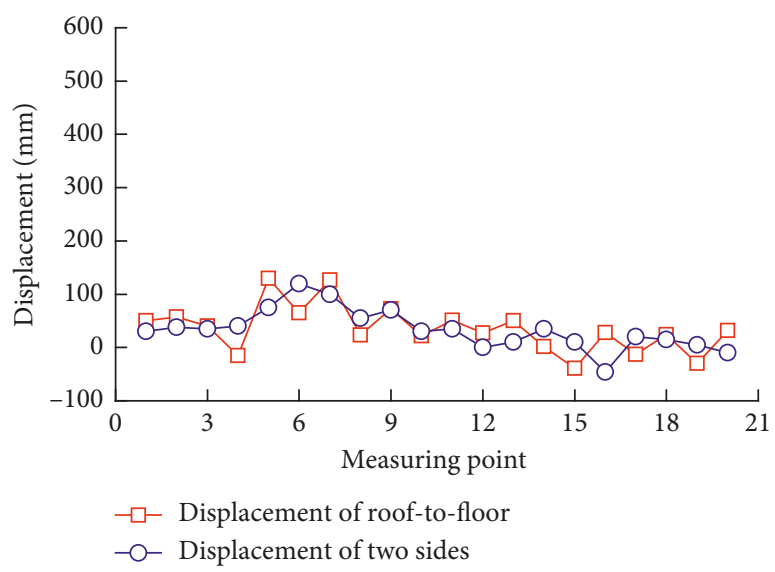

(c)

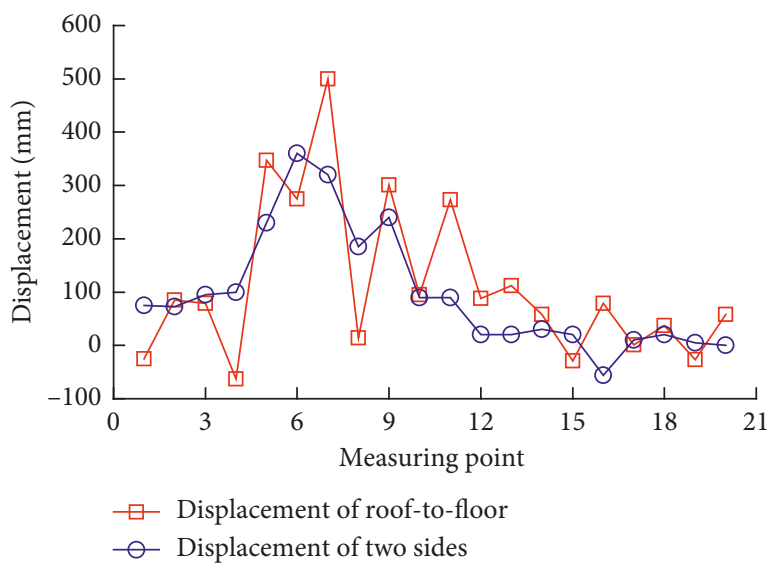

(e)

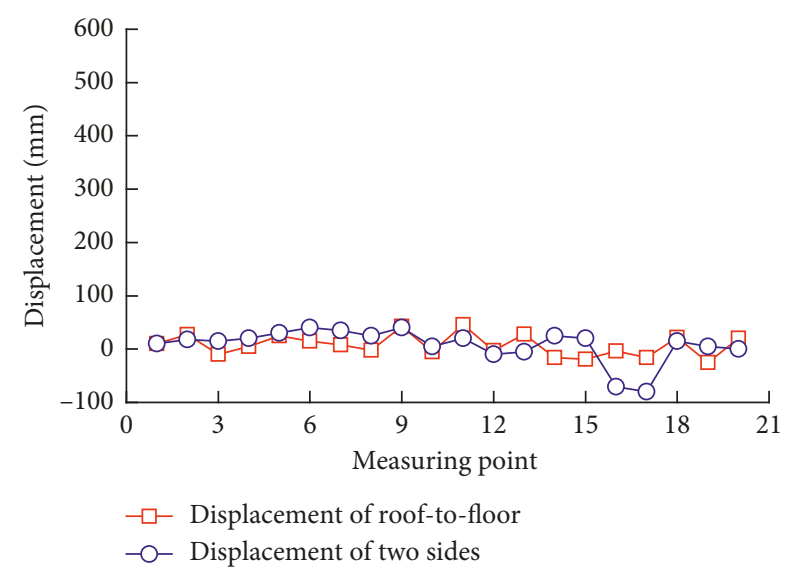

(b)

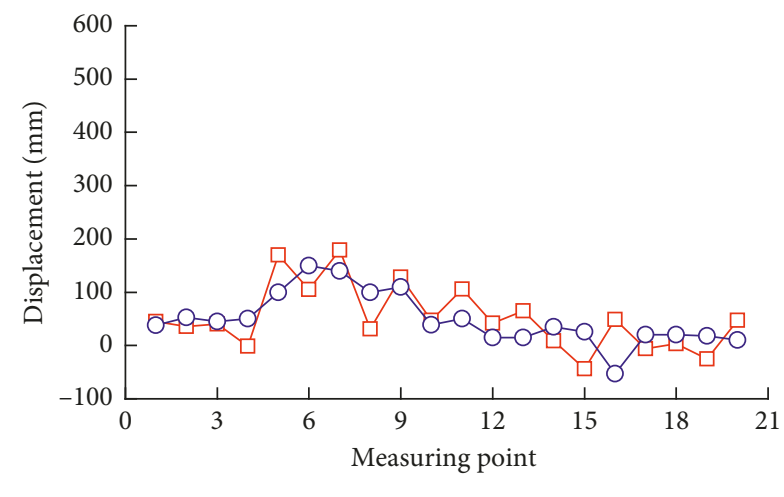

$-\square-$ Displacement of roof-to-floor

$-\cap$ Displacement of two sides

(d)

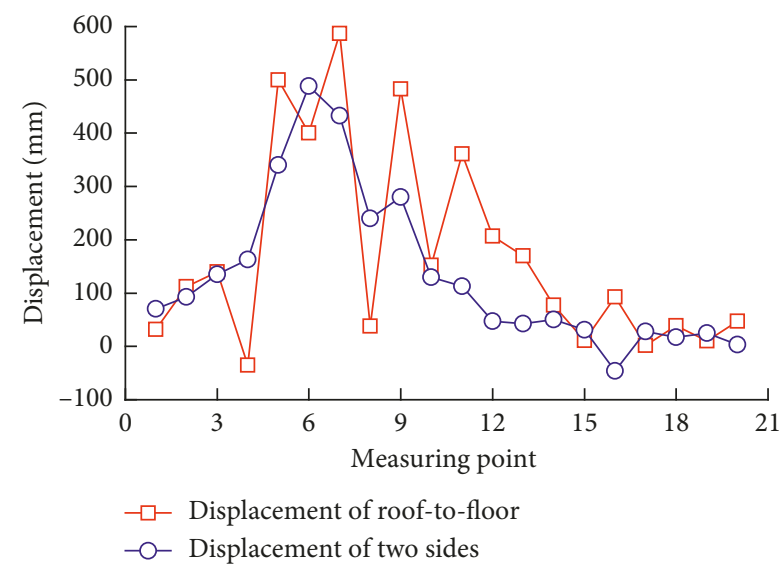

(f)

Figure 2: Deformation of roof roadway with panel 31010 retreat: (a) Feb 12, 2012; (b) Mar 10, 2012; (c) Apr 06, 2012; (d) Apr 30, 2012; (e) Jun 09, 2012; (f) Jul 07, 2012.

(3) After panel 21210 and panel 31010 are both mined, the roadway is located in the cumulated influence area of the two panels. The roadway shows severe deformations due to the significant increase in vertical stress compared to the case of mining panel 31010. The results of numerical simulation reveal the deformation mechanism of the roadway.

\section{Evolution of Mining-Induced Stress Contour}

The aforementioned results indicate that the mininginduced stress contour presents an external expansion type from the coal seam to the overlying strata in the numerical simulation. In the following section, the distribution of the mining-induced stress contour within the overlying 


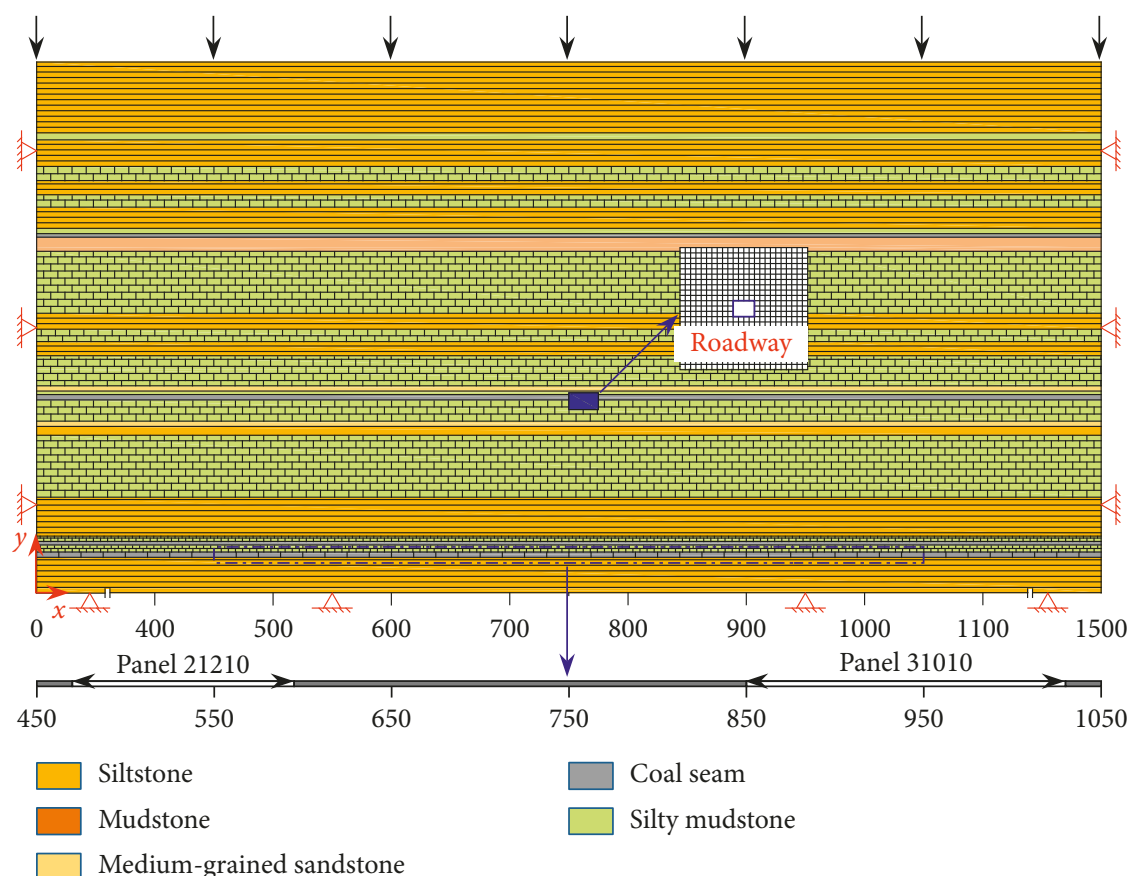

(a)

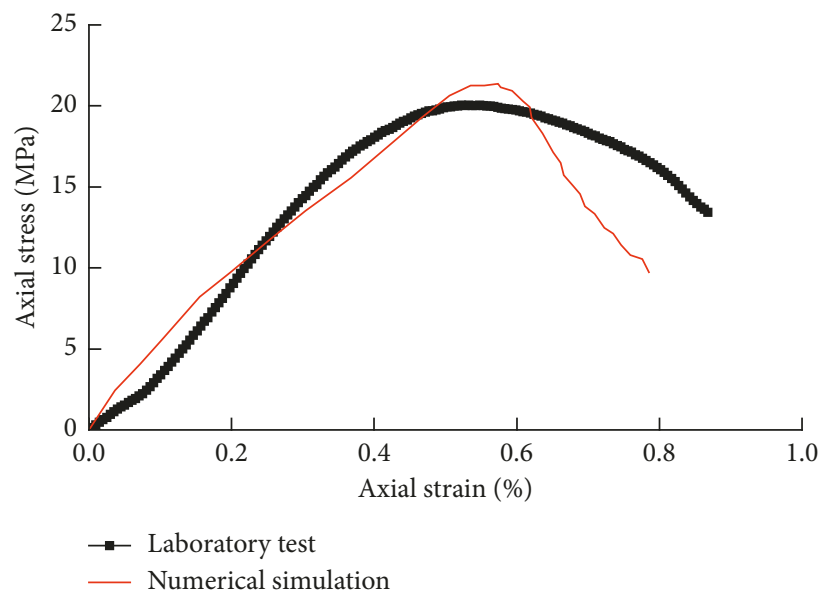

(b)

FIGURE 3: Numerical simulation: (a) numerical simulation model; (b) stress-strain curves in laboratory test and numerical simulation of the silty mudstone UCS test.

TABLE 1: Model parameters.

\begin{tabular}{lccccc}
\hline Rock layer & Elastic modulus $(\mathrm{GPa})$ & Poisson's ratio & Friction angle $\left(^{\circ}\right)$ & Tensile strength $(\mathrm{MPa})$ & Cohesive strength $(\mathrm{MPa})$ \\
\hline Siltstone & 18.5 & 0.20 & 35 & 4.80 & 5.70 \\
Medium grained sandstone & 17.8 & 0.25 & 32 & 3.37 & 3.67 \\
Silty mudstone & 14.0 & 0.28 & 28 & 2.85 & 3.50 \\
Mudstone & 3.5 & 0.32 & 25 & 1.50 & 3.25 \\
Coal seam & 2.5 & 0.32 & 22 & 1.05 & 1.75
\end{tabular}

strata is developed by means of theoretical analysis and physical simulation experiments.

3.1. Theoretical Analysis. The excavation of the panel causes movement of the overlying strata and results in a caving zone, fractured zone, and continuous deformation zone in the vertical direction $[15,17]$, which leads to stress redistribution. In fact, there is an inseparable relationship between overlying strata movement and mining-induced stress. On the basis of the strata subsidence law at different distances away from the coal seam, the distribution of mining-induced stress in overlying strata is analyzed below. 


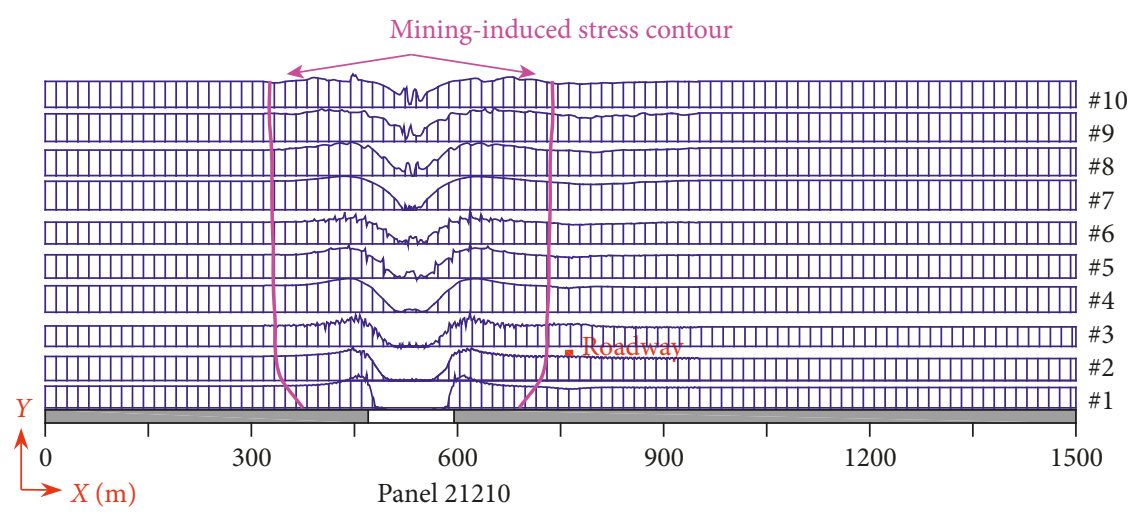

(a)

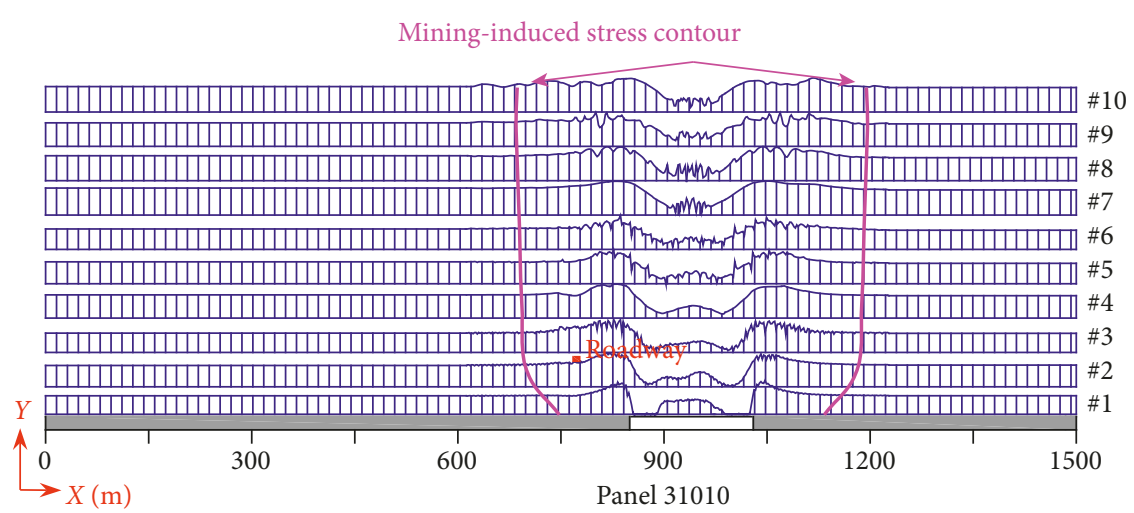

(b)

Mining-induced stress contour

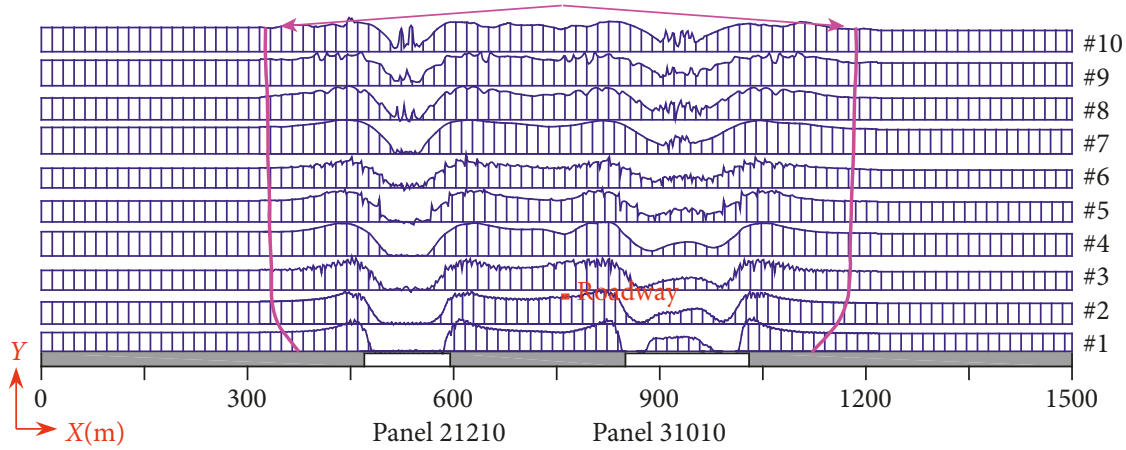

(c)

FiguRE 4: Mining-induced stress distribution: (a) mining only panel 21210; (b) mining only panel 31010; (c) mining both panel 21210 and 31010 .

3.1.1. Mining-Induced Subsidence. Figure 5 shows the mining-induced subsidence of the overlying strata in different heights of the overlying strata. Similar to the law of surface subsidence [10], Equation (1) can be used to express the distribution of subsidence at different heights of overlying strata:

$$
\omega(x, y)=\omega_{\max }(y) \cdot e^{-((x-L) / C(y))^{2}}
$$

where $x$ represents the coordinate in horizontal direction (m); $y$ represents the coordinate of vertical direction (m); $L$ represents the half width of the model $(\mathrm{m}) ; \omega(x, y)$ represents the subsidence at different heights of overlying strata $(\mathrm{m}) ; \omega_{\max }(y)$ represents the maximum subsidence at the same height $(\mathrm{m})$; and $C(y)$ is an undetermined coefficient.

In Equation (1), there are three undetermined coefficients, $L$, $\omega_{\max }(y)$, and $C(y)$, among which $L$ can be determined according to the width of the panel, while the other two undetermined coefficients cannot be obtained through theoretical calculation. Therefore, the subsidence in different heights of the overlying strata is fitted using Equation (1), and the results are as shown in Figures 5 and 6 and can be expressed as follows: 


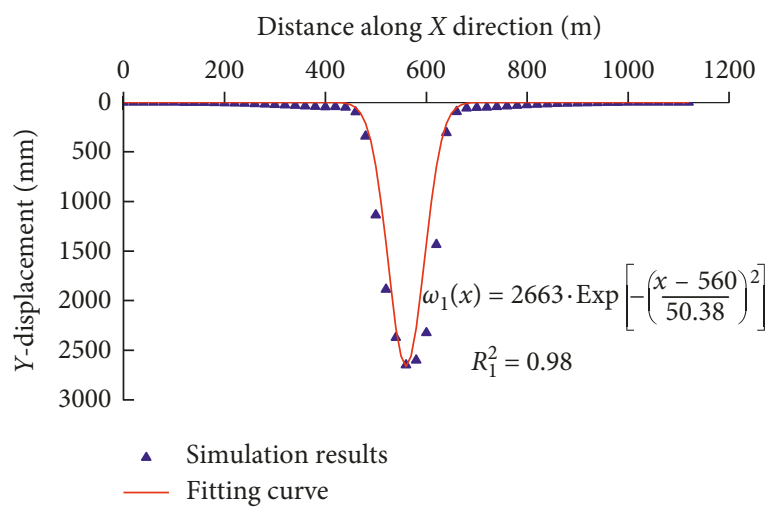

(a)

Distance along $X$ direction $(\mathrm{m})$

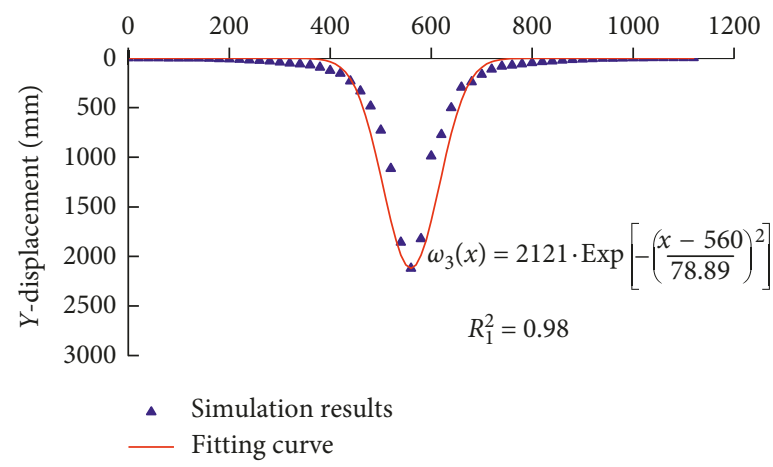

(c)

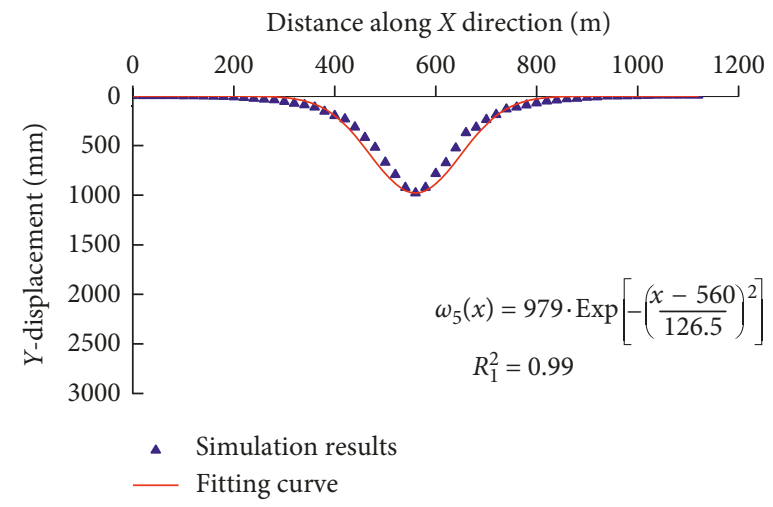

(e)

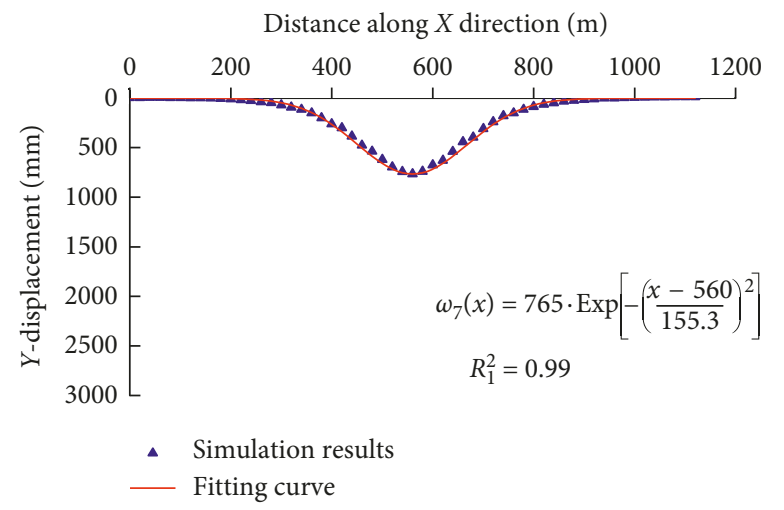

(g)

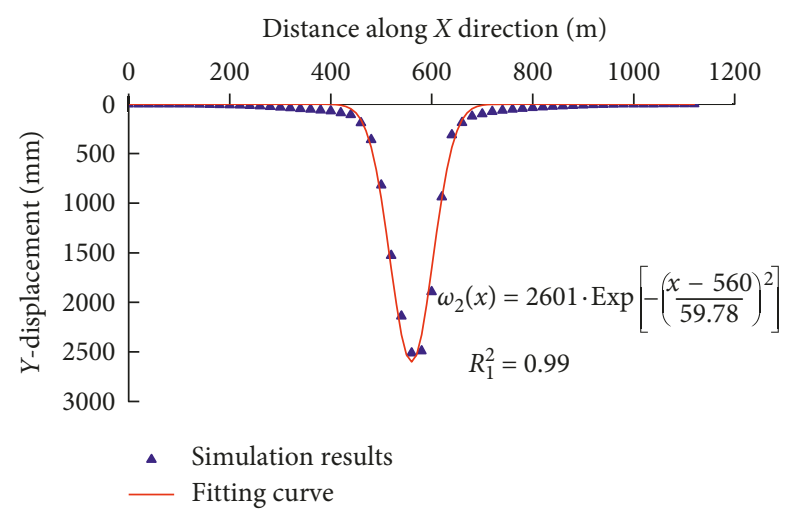

(b)

Distance along $X$ direction $(\mathrm{m})$

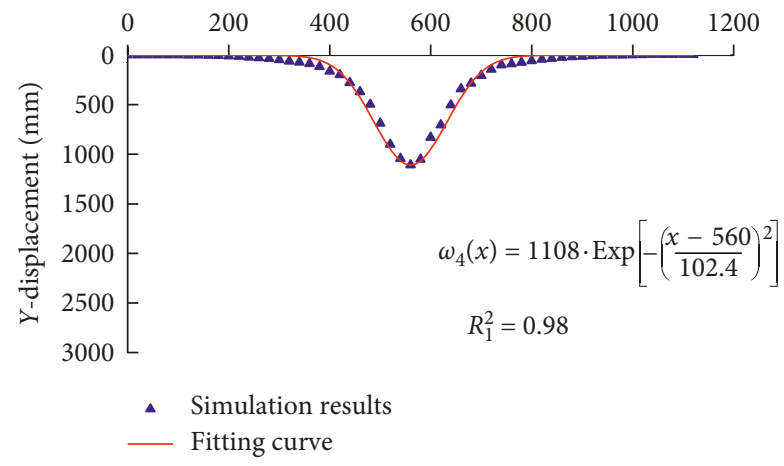

(d)

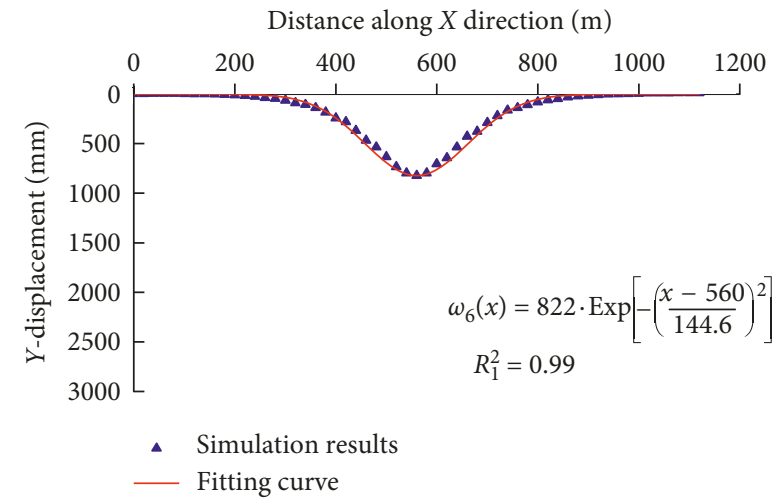

(f)

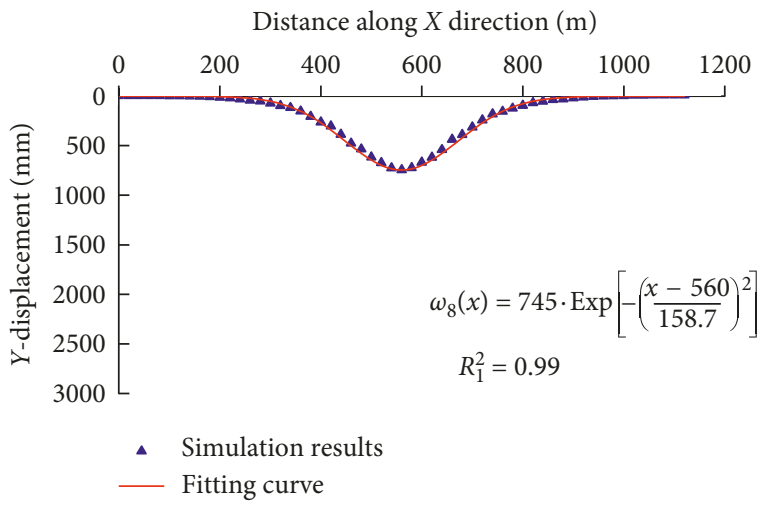

(h)

Figure 5: Subsidence in different heights of the overlying strata: (a) $Y=50 \mathrm{~m}$; (b) $Y=70 \mathrm{~m}$; (c) $Y=100 \mathrm{~m}$; (d) $Y=120 \mathrm{~m}$; (e) $Y=150 \mathrm{~m}$; (f) $Y=200 \mathrm{~m}$; (g) $Y=250 \mathrm{~m}$; (h) $Y=290 \mathrm{~m}$. 


$$
\left\{\begin{array}{l}
\omega_{\max }(y)=823+\frac{1820}{1+10^{-0.055 \cdot(107-y)}}, \quad R^{2}=0.99 \\
C(y)=\frac{162}{1+e^{-0.204 \cdot(y-95)},} \quad R^{2}=0.99
\end{array}\right.
$$

Equation (2) is substituted into Equation (1) to obtain the subsidence of the overlying strata at different heights, expressed as follows:

$$
\begin{aligned}
\omega(x, y)= & {\left[823+\frac{1820}{\left.1+10^{-0.055 \cdot(107-y)}\right]}\right.} \\
& \cdot e^{-\left\{\left((x-L)\left[1+e^{-0.204 \cdot(y-95)}\right]\right) / 162\right\}^{2}} .
\end{aligned}
$$

3.1.2. Relation of Mining-Induced Subsidence to Stress Distribution. According to Equation (3), the subsidence at any height in the overlying strata can be obtained. The load distribution can be obtained according to the relation between load distribution and deflection on an arbitrary beam [18]:

$$
q(x, y)=-E I \cdot \frac{d^{4} \omega(x, y)}{d x^{4}}
$$

where $E$ represents the elasticity modulus $(\mathrm{GPa})$ and $I$ represents the inertia moment $\left(\mathrm{m}^{4}\right)$.

The schematic diagram of the overlying strata subsidence is shown in Figure 7. By taking the first and second stratum under the surface as an example, the stress on the rock stratum is shown in Figure 7. It can be obtained from the equilibrium of first and second stratum that

$$
\left\{\begin{array}{l}
q_{0}+\gamma_{1} h_{1}-q_{1}(x, y)=-E_{1} I_{1} \cdot \frac{\partial \omega_{1}^{4}(x, y)}{\partial x^{4}} \\
q_{1}(x, y)+\gamma_{2} h_{2}-q_{2}(x, y)=-E_{2} I_{2} \cdot \frac{\partial \omega_{2}^{4}(x, y)}{\partial x^{4}},
\end{array}\right.
$$

where $\gamma_{1}$ and $\gamma_{2}$ represent the volume weight of the first and second strata $\left(\mathrm{kN} / \mathrm{m}^{3}\right)$ and $q_{0}$ represents the top boundary load on the stratum $(\mathrm{Pa})$. Because the first stratum is the ground rock stratum, $q_{0}$ equals to $0, q_{1}(x, y)$ represents the stress distribution on the floor boundary of the first rock stratum $(\mathrm{Pa}), q_{2}(x, y)$ represents the stress distribution on the floor boundary of second rock stratum $(\mathrm{Pa}), h_{1}$ and $h_{2}$ represent the thickness of the first and second strata $(\mathrm{m})$, $E_{1}$ and $E_{2}$ represent the elasticity modulus of the first and second strata $(\mathrm{GPa})$, and $I_{1}$ and $I_{2}$ represent the inertia moment of the first and second strata $\left(\mathrm{m}^{4}\right)$.

The equilibriums of $i \ldots n$ overlying strata are shown in Equation (6):

$$
\left\{\begin{array}{l}
\gamma_{i} h_{i}+q_{i-1}(x, y)-q_{i}(x, y)=-E_{i} I_{i} \cdot \frac{\partial \omega_{i}^{4}(x, y)}{\partial x^{4}}, \\
\vdots \\
\gamma_{n} h_{n}+q_{n-1}(x, y)-q_{n}(x, y)=-E_{n} I_{n} \cdot \frac{\partial \omega_{n}^{4}(x, y)}{\partial x^{4}},
\end{array}\right.
$$

where $\gamma_{i}$ and $\gamma_{n}$ represent the volume weight of the $i$-th and $n$-th strata $\left(\mathrm{kN} / \mathrm{m}^{3}\right) ; q_{i-1}(x, y)$ represents the stress distribution on the floor boundary of the $(i-1)$ th rock stratum $(\mathrm{Pa}) ; q_{n-1}(x, y)$ represents the stress distribution on the floor boundary of $(n-1)$ th rock stratum $(\mathrm{Pa}) ; h_{i}$ and $h_{n}$ represent the thickness of the $i$-th and $n$-th strata $(\mathrm{m}) ; E_{i}$ and $E_{n}$ represent the elasticity modulus of the $i$-th and $n$-th strata (GPa); and $I_{i}$ and $I_{n}$ represent the inertia moment of the $i$-th and $n$-th strata $\left(\mathrm{m}^{4}\right)$.

By adding each left item and each right item of Equations (5) and (6), the stress distribution of an arbitrarily overlying stratum can be obtained by the following:

$$
q_{n}(x, y)=\sum_{i=1}^{n} \gamma_{i} h_{i}+\sum_{i=1}^{n} E_{i} I_{i} \cdot \frac{\partial \omega_{i}^{4}(x, y)}{\partial x^{4}} .
$$

According to the definition of mining-induced stress contour, that is, $q_{n}(x, y)=1.05 \cdot \sum_{i=1}^{n} \gamma_{i} h_{i}$, the previous equation can be simplified and taken as $q_{n}(x, y)=\sum_{i=1}^{n} \gamma_{i} h_{i}$. Therefore, the distribution characteristics of the mininginduced stress contour at any height of overlying strata can be obtained according to Equation (8):

$$
\sum_{i=1}^{n} E_{i} I_{i} \cdot \frac{\partial \omega_{i}^{4}(x, y)}{\partial x^{4}}=0 .
$$

According to Equation (8) and numerical simulation results, the distribution characteristic of the mining-induced stress contour is depicted in Figure 8. The results of the numerical simulation correlate well with theoretical results.

3.2. Physical Simulation. The physical simulation model shown in Figure 9 was constructed in order to study the mining-induced stress distribution in the overlying strata. The model composed of seven rock layers has dimensions of $2500 \mathrm{~mm} \times 1300 \mathrm{~mm} \times 200 \mathrm{~mm}$ (length $\times$ height $\times$ width $)$. A scaled physical model has to be designed in accordance with the laws of the similarity theory $[19,20]$. As per these laws, the parameters should satisfy the fundamental condition of the similarity theory.

$$
\left\{\begin{array}{l}
\frac{C_{\sigma}}{C_{\rho} \times C_{L}}=1 \\
C_{\sigma}=\frac{\sigma_{P}}{\sigma_{m}}, \\
C_{\rho}=\frac{\rho_{P}}{\rho_{m}}, \\
C_{L}=\frac{L_{P}}{L_{m}},
\end{array}\right.
$$

where $C_{\sigma}$ is the similarity constant for strength, $C_{\rho}$ is the similarity constant for density, and $C_{L}$ is the similarity constant for geometry; and the subscript $P$ denotes the prototype based on field conditions, while $m$ represents the physical model.

The geometric similarity ratio was $1: 100$, weight similarity ratio was $1: 1.25$, rigidity similarity ratio was $1: 1.67$, 


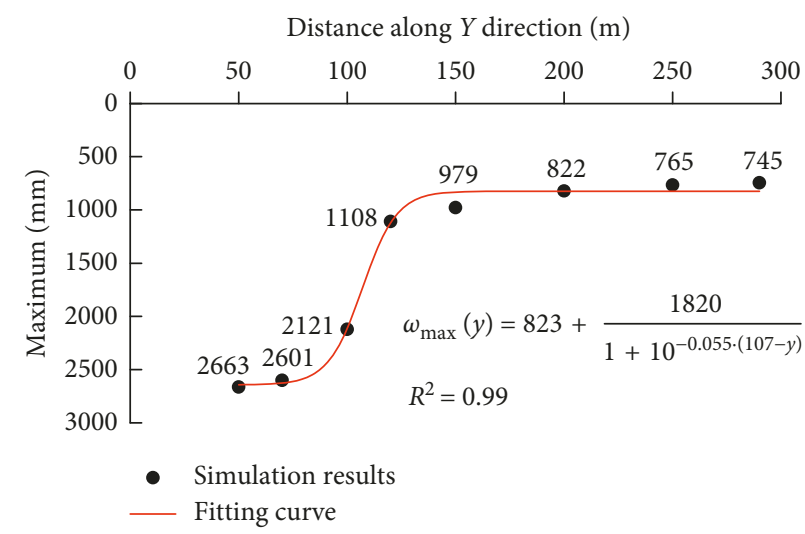

(a)

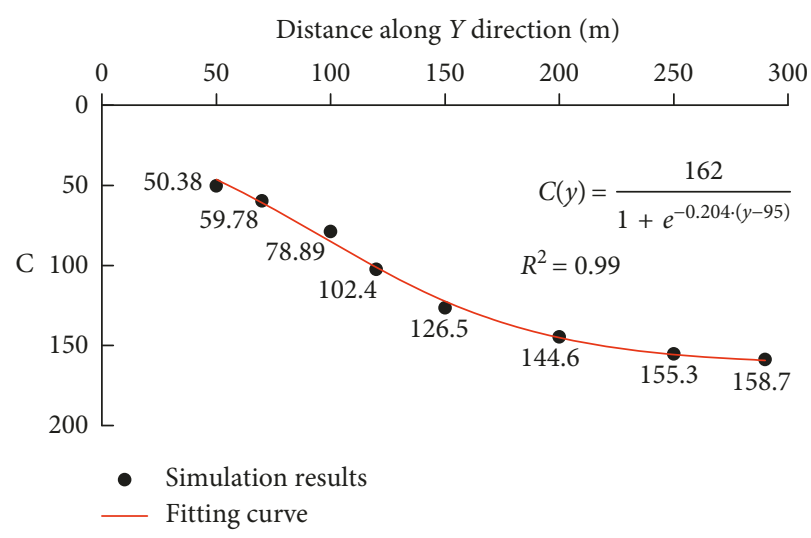

(b)

FIGURE 6: Fitting curves of undetermined coefficient: (a) fitting curve of $\omega_{\max }(y)$; (b) fitting curve of $C(y)$.

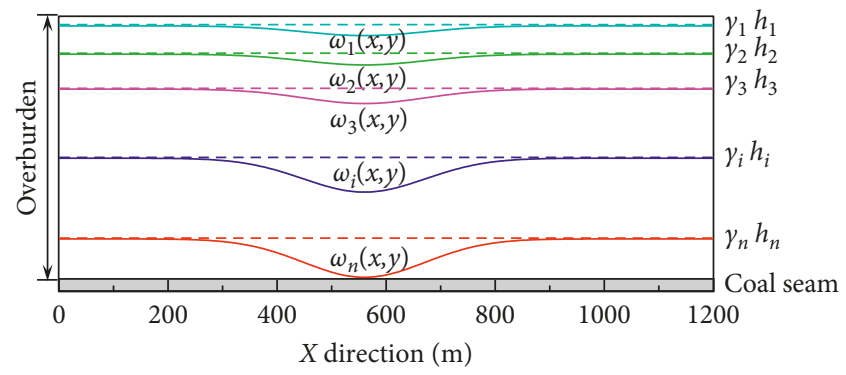

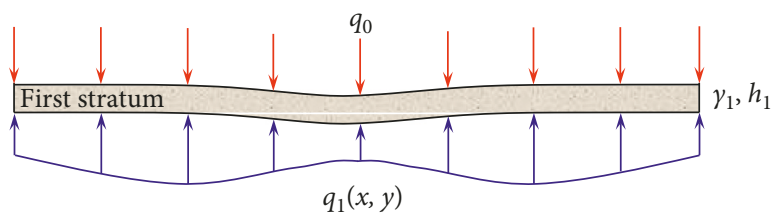

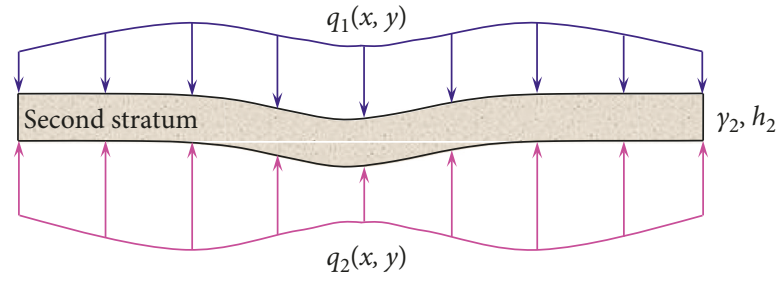

(b)

FIGURE 7: Mining-induced subsidence in the overlying strata: (a) overlying strata subsidence; (b) mining-induced stress in the overlying strata.

and stress similarity ratio was $1: 1.67$. River sand was used as aggregate and gypsum, and calcium carbonate was used as to allow for the cohesion of each layer. The loose bed was composed of the river sand and dry sawdust. The mixture material ratio and the physical and mechanical parameters of the strata are presented in Table 2. Four vertical survey lines including four points in each line were installed in the model to monitor the mininginduced stress. BW-type pressure cells embedded in each rock layer in advance were adopted for stress monitoring during the entire mining process (Figure 9). In the experiment, the panel was advanced for an accumulative total length of $1,700 \mathrm{~mm}$. At both boundaries of the model, $400 \mathrm{~mm}$ coal pillar remained to eliminate the boundary influence. The panel was advanced by $50 \mathrm{~mm}$ at an interval of $15 \mathrm{~min}$.

The distance between the mining-induced stress contour and the mining boundary is shown in Table 3 .

(1) Taking measuring point 2-2 as an example, the vertical stress of this measuring point fluctuates during initial excavation. With the panel gradually approaching the measuring point, the stress

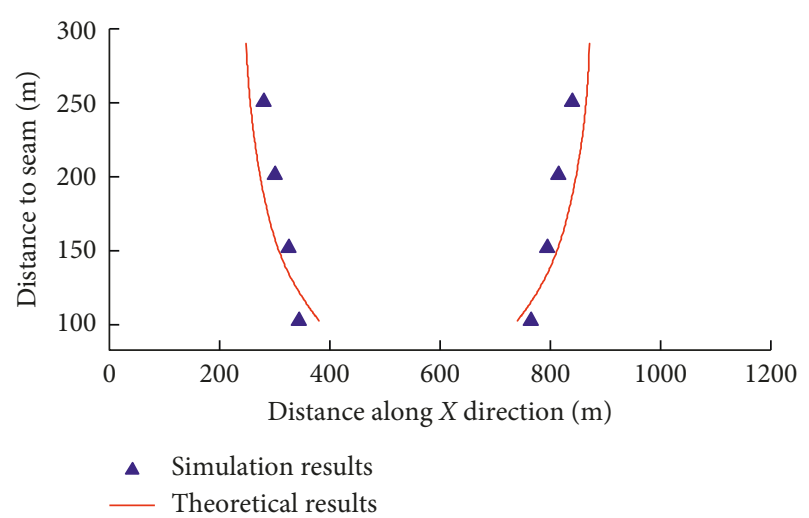

Figure 8: Comparison between numerical simulation and theoretical results.

gradually increases to the peak, and then gradually decreases.

(2) During the mining process, as the vertical distance between the measuring point and the coal seam increases, the influence range of mining-induced 


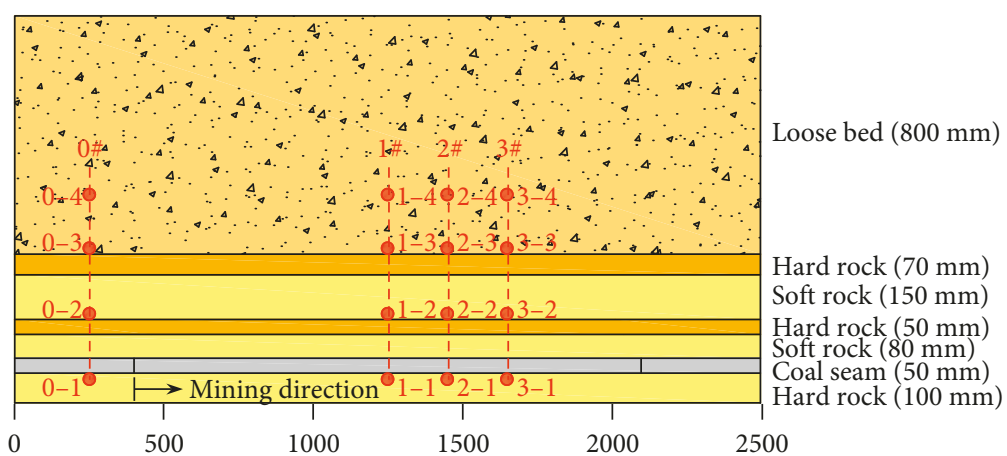

- Stress monitoring point

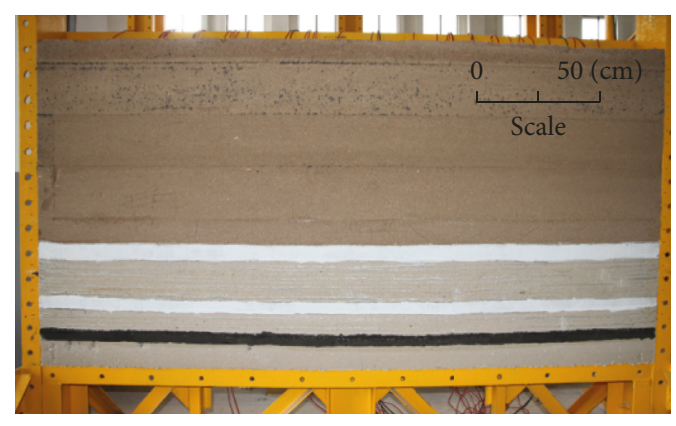

(b)

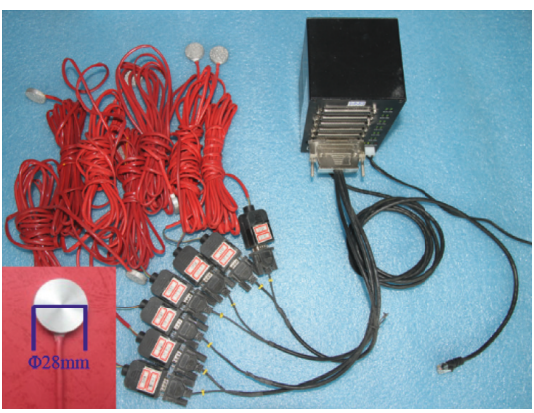

(c)

Figure 9: Physical model and stress monitoring system: (a) plan of physical simulation model (unit: m); (b) front view of physical model; (c) stress monitoring system.

TABle 2: Mixture material ratio and the physical and mechanical parameters of the strata.

\begin{tabular}{|c|c|c|c|c|c|c|c|c|c|c|c|c|c|}
\hline \multirow[t]{2}{*}{ No. } & \multirow[t]{2}{*}{ Lithology } & \multicolumn{4}{|c|}{ Material (kg) } & \multicolumn{2}{|c|}{$\begin{array}{l}\text { Bulk density } \\
\left(\mathrm{kN} / \mathrm{m}^{3}\right)\end{array}$} & \multicolumn{2}{|c|}{$\begin{array}{l}\text { Elastic modules } \\
\qquad(\mathrm{GPa})\end{array}$} & \multicolumn{2}{|c|}{$\begin{array}{c}\text { Uniaxial } \\
\text { compressive } \\
\text { strength }(\mathrm{Mpa})\end{array}$} & \multicolumn{2}{|c|}{ Poisson's ratio } \\
\hline & & Sand & $\mathrm{CaCO}_{3}$ & Gypsum & Water & Prototype & Model & Prototype & Model & Prototype & Model & Prototype & Model \\
\hline 1 & Loose bed & \multicolumn{4}{|c|}{ Sand : sawdust $=10: 1$} & $18 \sim 22.5$ & 12.2 & $0.1 \sim 5.0$ & 0.00093 & $5 \sim 13$ & 0.0033 & $0.35 \sim 0.40$ & 0.35 \\
\hline 2 & Hard rock & 63.36 & 3.80 & 8.87 & 8.45 & 24.7 & 15 & 22 & 0.13174 & 37 & 0.2220 & 0.20 & 0.20 \\
\hline 3 & Soft rock & 126.72 & 17.74 & 7.60 & 16.90 & 20.2 & 15 & 8 & 0.04790 & 15 & 0.0900 & 0.28 & 0.28 \\
\hline 4 & Coal seam & 44.35 & 4.44 & 1.90 & 5.63 & 13.5 & 15 & 3 & 0.01796 & 12 & 0.0700 & 0.28 & 0.28 \\
\hline
\end{tabular}

stress enlarges gradually. For example, the stress in measuring point $2-1$ starts to increase as the distance between the measuring point and the panel is $30 \mathrm{~m}$. While the distance is $60 \mathrm{~m}$ for measuring point $2-4$. When the panel is continuously advanced forward, there is also the same stress development law on the other measuring points.

Therefore, when the panel is mined, as the vertical distance between the measuring point and the coal seam increases, the influence ranges of mining-induced stress are $28 \mathrm{~m}, 43 \mathrm{~m}, 54 \mathrm{~m}$, and $60 \mathrm{~m}$ on average. The influence distance of mining-induced stress gradually enlarges. The mining-induced stress contour presents a concave-upward type from the coal seam to the overlying strata. These conclusions are consistent with the numerical simulation results.
TABLE 3: Distance between the mining-induced stress contour and the edge of panel (unit: $\mathrm{m}$ ).

\begin{tabular}{lccccc}
\hline \multirow{2}{*}{ Measuring point } & \multicolumn{5}{c}{ Survey line } \\
& 0 & 1 & 2 & 3 & Average value \\
\hline 1 & 30 & 25 & 30 & 30 & 28 \\
2 & 40 & 45 & 45 & - & 43 \\
3 & 55 & 50 & 55 & 55 & 54 \\
4 & 60 & 60 & 60 & 60 & 60 \\
\hline
\end{tabular}

\section{Method to Design Coal Pillar for Lateral Roof Roadway}

Mining-induced stress contour is the curve to judge whether the overlying strata is affected by coal mining. Inside of it, stress inside the contour is redistributed, whereas outside of it, the overlying strata are still within the in situ stress area. 


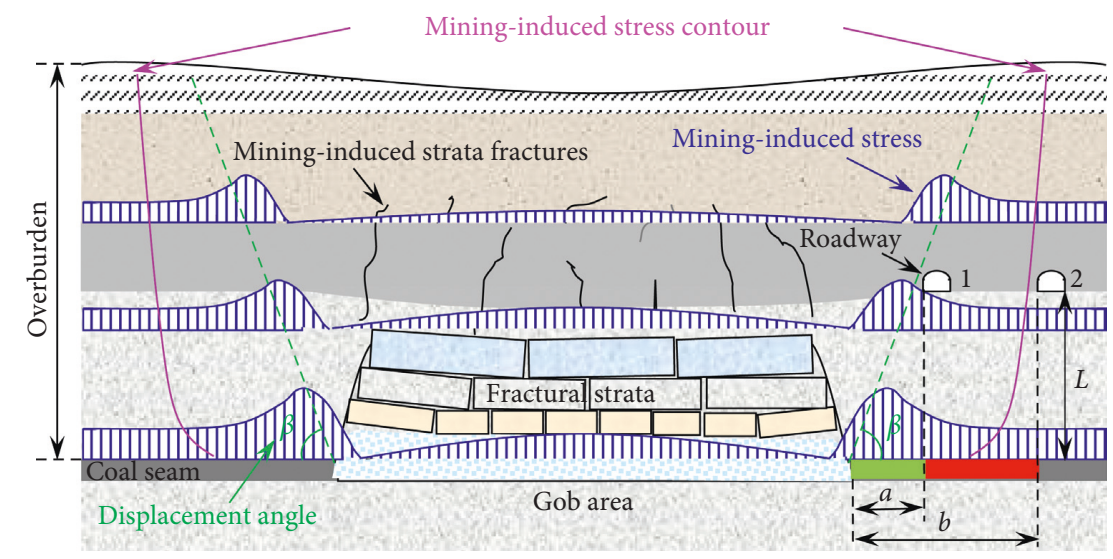

Figure 10: Method to design coal pillar for lateral roof roadway. $\beta$ represents the displacement angle, 1 and 2 represent the roadways in different positions, $a$ and $b$ represent the width of the coal pillar, and $L$ represents the vertical distance between the roadway and coal seam.

As shown in Figure 10, the mining-induced stress contour extends in a concave way from the coal seam to surface. The higher the coal seam, the larger the horizontal distance between stress contour and longwall mining edge. Therefore, the width of coal pillar should be designed according to stress contour and the position of protectors to ensure that the lateral roof roadway is not affected by excavation. The detailed steps of this method are as follows: determining mining-induced stress contour based on actual geological conditions; calculating the intersection of the level of lateral roof roadway and mining-induced stress contour and making its projection point on the coal seam; the distance between projection point and longwall mining edge is the width of the coal pillar.

A schematic diagram of mining-induced stress distribution in the overlying strata is shown in Figure 10. When the vertical distance between the roadway and the coal seam is $L$, the width of coal pillar designed according to the traditional displacement angle of rock strata is $a$. It is obvious that the roadway located at position 1 would be damaged because it is still located within the mininginduced stress concentration zone. Thus, the coal pillar according to the traditional method cannot ensure that no deformation would occur to the roadway. According to the method outlined in this paper, the width of the coal pillar for roadway would be $b$, and the roadway would be located in position 2 . The roadway is outside the mining-induced stress contour and is not subject to the influence by excavation, which meets the design requirements. Compared with the traditional method, the modified method takes into account the distribution law of mining-induced stress within the overlying strata, so it can better meet engineering demands.

\section{Field Verifications}

5.1. Case 1: Longwall Panel 31010 of Pingdingshan Coal Mine. The lateral roof roadway was still located in the overlapping influence area of panels 21210 and 31010, and the roadway was damaged. The traditional design method ignores both the strata deformation and the mining-induced stress distribution of the overlying strata. Now, the coal pillar was redesigned based on the new methodology. According to the aforementioned results, the average distance between the mining-induced stress contour and the edge of panel 21210 and 31010 was shown in Table 4.

As shown in Figure 1, the average vertical distance between the lateral roof roadway and the \#10 coal seam is $85 \mathrm{~m}$. The coal pillar is $143 \mathrm{~m}$ and $158 \mathrm{~m}$ in width for panel 21210 and 31010 based on the new method according to Table 4 . The lateral roof roadway is not influenced by mining of the panel 21210 because the actual size of coal pillar is wider than the design value. Because the width of the coal pillar in the roadway of panel 31010 is significantly smaller than that of panel 21210, the lateral roof roadway had undergone serious deformation. According to the method, the coal pillar's width is $158 \mathrm{~m}$ for the lateral roof roadway of longwall panel 31010.

\subsection{Case 2: Longwall Panel 31110 of Pingdingshan Coal Mine}

5.2.1. Mining Conditions. By taking Pingdingshan No. 1 Coal Mine as an example for designing coal pillar for lateral roof roadway, the deformation law of the roadway was also studied when mining panel 31100 . The average burial depth of panel 31100 is $750 \mathrm{~m}$. The thickness of the coal seam is $2.4 \mathrm{~m}$, and the average dip angle is $6.5^{\circ}$. With a section of $4.2 \mathrm{~m}$ wide and $3 \mathrm{~m}$ high, the roadway is supported by the combination of bolt and anchor. The bolt is $20 \mathrm{~mm}$ in diameter and $2.2 \mathrm{~m}$ in length with raw and line space of $700 \mathrm{~mm} \times 700 \mathrm{~mm}$. The anchor is $20 \mathrm{~mm}$ in diameter and $7 \mathrm{~m}$ in length. The lateral roof roadway is adjacent to panel 31100 passenger roadway. The vertical distance between the lateral roof roadway and the coal seam is $100 \mathrm{~m}$. According to the method, the coal pillar's width should not be less than $160 \mathrm{~m}$, and the actual width of coal pillar for roadway is $150 \sim 175 \mathrm{~m}$.

5.2.2. Field Measurement and Theoretical Analysis. In order to observe the deformation characteristics of the lateral roof roadway under the mining impact of panel 31100 , a total of 12 measurement points at intervals of $100 \mathrm{~m}$ were arranged in the roadway. During the later observation, the data of 
TABLE 4: Distance between mining-induced stress contour and edge of panel.

\begin{tabular}{|c|c|c|c|}
\hline \multirow[t]{2}{*}{ No. } & \multirow[t]{2}{*}{ Distance between coal seam and measuring line $(\mathrm{m})$} & \multicolumn{2}{|c|}{$\begin{array}{l}\text { Average distance between mining-induced } \\
\text { stress contour and edge of panel }(\mathrm{m})\end{array}$} \\
\hline & & Panel 21210 & Panel 31010 \\
\hline$\# 1$ & 3 & 103 & 105 \\
\hline$\# 2$ & 43 & 133 & 140 \\
\hline$\# 3$ & 85 & 143 & 158 \\
\hline$\# 4$ & 143 & 143 & 159 \\
\hline$\# 5$ & 193 & 146 & 160 \\
\hline \#6 & 243 & 146 & 162 \\
\hline$\# 7$ & 293 & 147 & 163 \\
\hline$\# 8$ & 343 & 148 & 165 \\
\hline$\# 9$ & 393 & 149 & 167 \\
\hline$\# 10$ & 443 & 151 & 168 \\
\hline
\end{tabular}

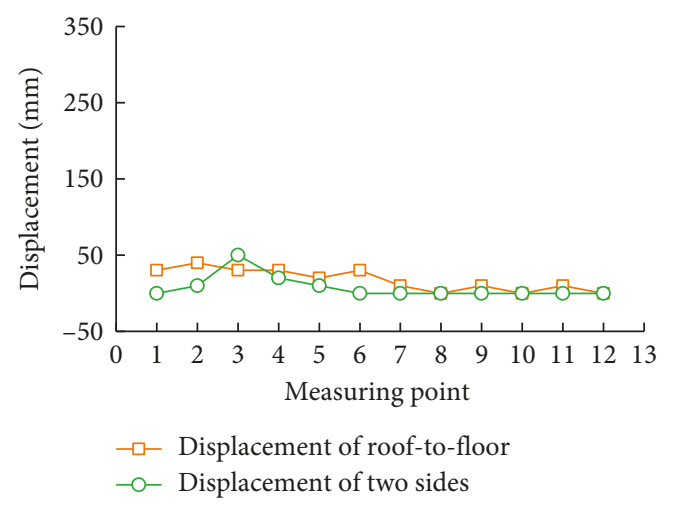

(a)

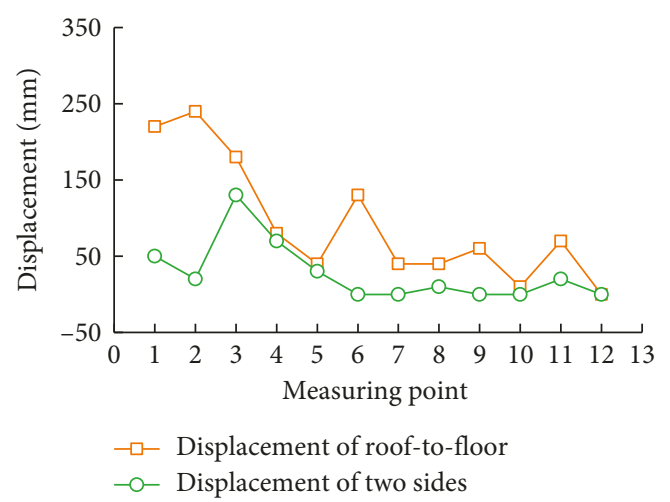

(c)

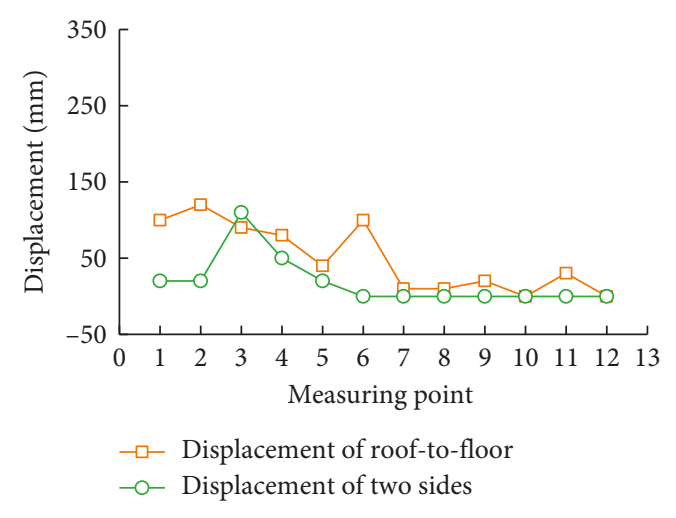

(b)

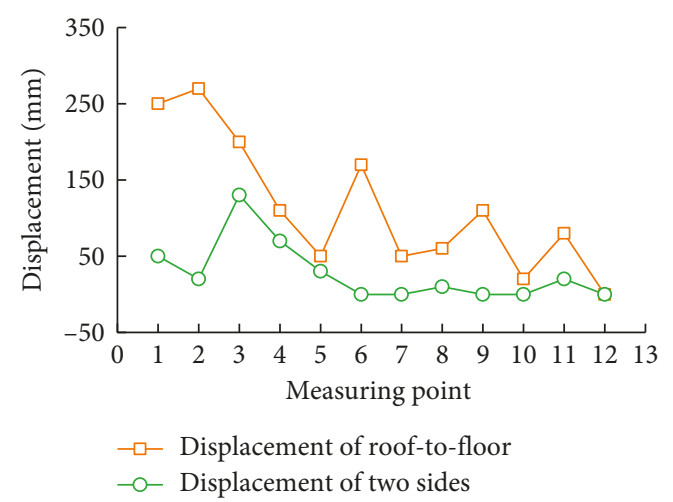

(d)

Figure 11: Deformation of roof roadway with panel 31100 retreat: (a) Oct 17, 2013; (b) Nov 14, 2013; (c) Dec 13, 2013 ; (d) Jan 16, 2014.

displacement of roof-to-floor and two sides are measured by the cross-distributing point method and the initial data are obtained on Oct. 10, 2013.

Field measurement has been carried out for 14 times. The results of displacement of roof-to-floor and two sides are shown in Figure 11. After the mining of panel 31100, slight deformations were observed. The maximum deformation of roadway was $270 \mathrm{~mm}$, which could satisfy normal use without any repair. Therefore, the coal pillar designed according to the method can definitely meet engineering practice.

\section{Conclusion}

(1) Evolution of mining-induced stress was simulated by numerical and physical simulations. The stress of the overlying strata was redistributed during excavation. A contour line of 1.05 times the in situ stress is used to define the mining-induced stress contour. Mining-induced stress contour was used to determine whether the stress of the overlying strata was redistributed or not. Stress inside the contour is redistributed while that outside the contour the 
overlying strata is still within the in situ stress area. Mining-induced stress contour presents a concaveupward type from coal seam to the overlying strata that cannot be merged into a straight one.

(2) A method was proposed to design coal pillar for the lateral roof roadway based on the evolution of mining-induced contour. Compared with the conventional method, the method outlined in this paper made up for the deficiency which ignored the variations of the internal strata deformation law as well as stress distribution characteristics.

(3) When the vertical distance between the lateral roof roadway and the coal seam was $100 \mathrm{~m}$ in longwall panel 31100 of Pingdingshan No. 1 coal mine, the width of the coal pillar was $160 \mathrm{~m}$ based on the aforementioned method, and the maximum deformation of roadway was $270 \mathrm{~mm}$. The new method can definitely meet engineering demands.

\section{Data Availability}

The data used to support the findings of this study are available from the corresponding author upon request.

\section{Conflicts of Interest}

The authors declare that there are no conflicts of interest regarding the publication of this paper.

\section{Acknowledgments}

This work was supported by the Shandong Provincial Natural Science Foundation of China (ZR2018BEE001) and Scientific Research Foundation of SDUST for Recruited Talents (2017RCJJ006). We would like to thank Editage (http://www.editage.cn) for English language editing.

\section{References}

[1] L. Yuan, "Technique of coal mining and gas extraction without coal pillar in multi-seam with low permeability," Journal of Coal Science and Engineering (China), vol. 15, no. 2, pp. 120-128, 2009.

[2] B. B. Tati, "Multi-seam coal mining," Journal of the South African Institute of Mining and Metallurgy, vol. 111, no. 4, pp. 231-242, 2011.

[3] N. Zhang, L. Yuan, C. Wang et al., "Deformation characteristics and stability analysis of roof roadway in distressed mining," Journal of China Coal Science, vol. 36, no. 11, pp. 1784-1789, 2011

[4] C. Wang, Z. S. Du, N. C. Zhang et al., "Study on surrounding rock control for mining roadway of the overlying protected seam in ascending de-stressed mining," Journal of Mining and Safety Engineering, vol. 29, no. 2, pp. 220-225, 2012.

[5] C. Wang, N. Zhang, G. C. Li et al., "Control principles for roadway roof stabilization in different zones during ascending mining," Journal of China University and Mining Technology, vol. 41, no. 4, pp. 544-550, 2012.

[6] C. O. Aksoy, H. Kose, T. Onargan et al., "Estimation of limit angle using laminated displacement discontinuity analysis in the Soma coal field, Western Turkey," International Journal of
Rock Mechanics and Mining Sciences, vol. 41, no. 4, pp. 547-556, 2004.

[7] Y. M. Yu, H. Y. Dai, and Z. J. He, "Mining design for shaft and industry square pillar and practice in No. 6 coal mine in Changguang mining district," Journal of Mining Safety Sciences, vol. 25, no. 2, pp. 202-206, 2008.

[8] Z. Zhou and Q. F. Li, "Safety coal pillar design of coal mining under railway," Mineral Engineering Research, vol. 27, no. 3, pp. 23-27, 2012.

[9] S. J. Chen, H. L. Wang, H. Y. Wang et al., "Strip coal pillar design based on estimated surface subsidence in eastern China," Rock Mechanics and Rock Engineering, vol. 49, no. 9, pp. 3829-3838, 2016.

[10] H. Kratzsch, Mining Subsidence Engineering, Springer-Verlag, Berlin, Heidelberg, Germany, 1983.

[11] State Bureau of Coal Industry, Regulations of Coal Pillar Design and Extraction for Buildings, Water Bodies, Railways, Main Shafts and Roadways, Coal Industry Press, Beijing, China, 2000.

[12] J. L. Xu, Green Mining of Coal Mine, China University of Mining and Technology Press, Xuzhou, China, 2010.

[13] B. Christaras and M. Chatziangelou, "Blastability quality system (BQS) for using it, in bedrock excavation," Structural Engineering and Mechanics, vol. 51, no. 5, pp. 823-845, 2014.

[14] M. Mohammadi and H. Tavakoli, "Comparing the generalized Hoek-Brown and Mohr-Coulomb failure criteria for stress analysis on the rocks failure plane," Geomechanics and Engineering, vol. 9, no. 1, pp. 115-124, 2015.

[15] M. G. Qian, P. W. Shi, and J. L. Xu, Mine Pressure and Ground Control, China University of Mining and Technology Press, Xuzhou, China, 2010.

[16] D. Z. Song, E. Y. Wang, J. K. Xu et al., "Numerical simulation of pressure relief in hard coal seam by water jet cutting," Geomechanics and Engineering, vol. 8, no. 4, pp. 495-510, 2015.

[17] V. Palchik, "Experimental investigation of apertures of mining-induced horizontal fractures," International Journal of Rock Mechanics and Mining Sciences, vol. 47, no. 3, pp. 502-508, 2010.

[18] J. M. Gere, Mechanics of Materials, Thomson Learning, Inc., Australia, 2004.

[19] B. Ghabraie, G. Ren, J. Smith et al., “Application of 3D laser scanner, optical transducers and digital image processing techniques in physical modelling of mining-related strata movement," International Journal of Rock Mechanics and Mining Sciences, vol. 80, no. 2, pp. 219-230, 2015.

[20] B. Ghabraie, G. Ren, X. Zhang et al., "Physical modelling of subsidence from sequential extraction of partially overlapping longwall panels and study of substrata movement characteristics," International Journal of Coal Geology, vol. 140, no. 2, pp. 71-83, 2015. 


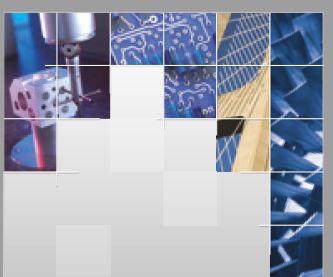

\section{Enfincering}
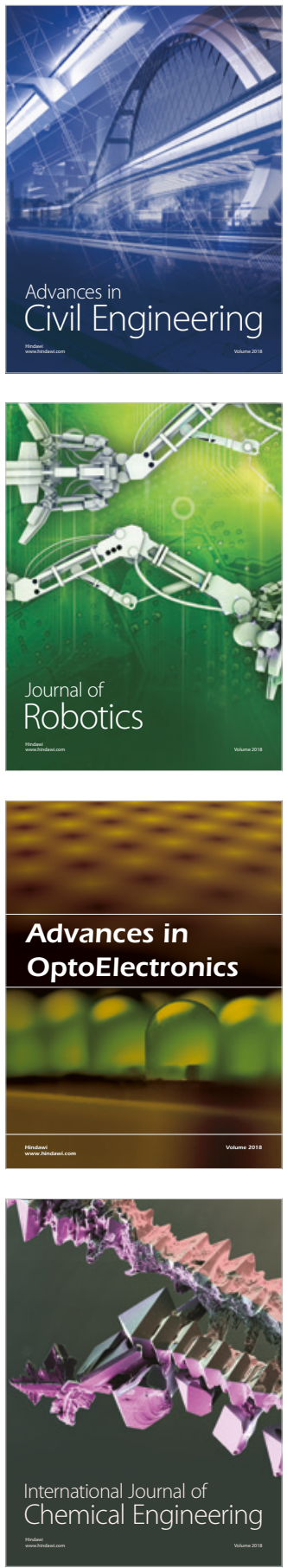

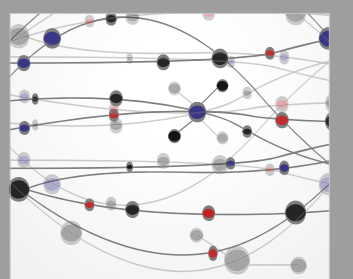

\section{Rotating \\ Machinery}

The Scientific World Journal

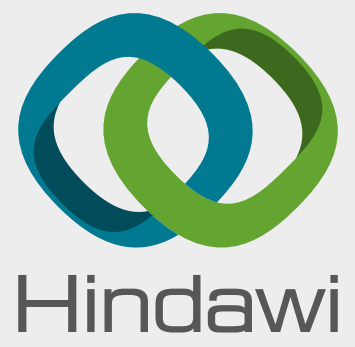

Submit your manuscripts at

www.hindawi.com
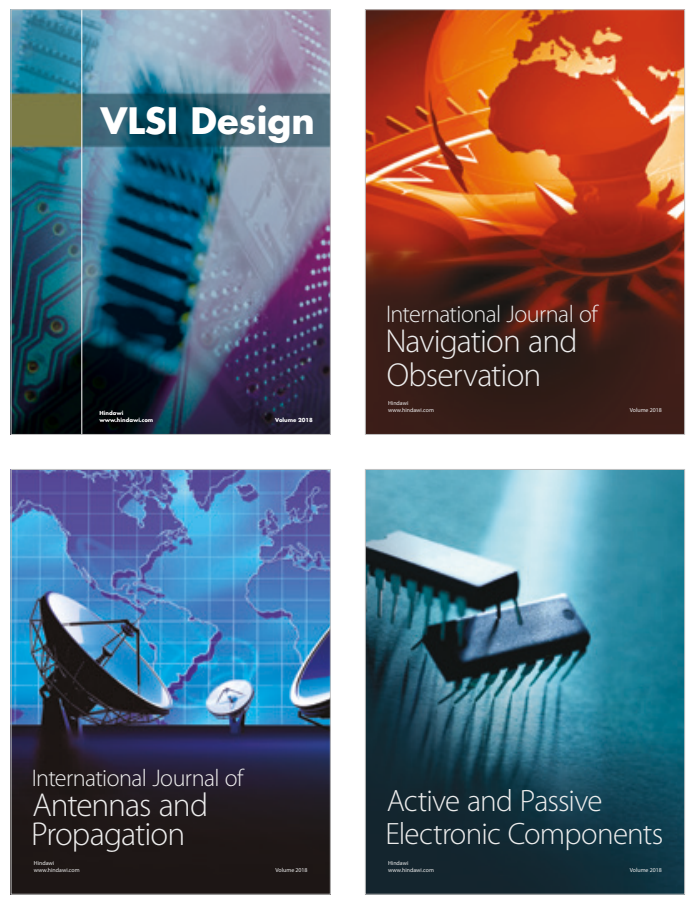
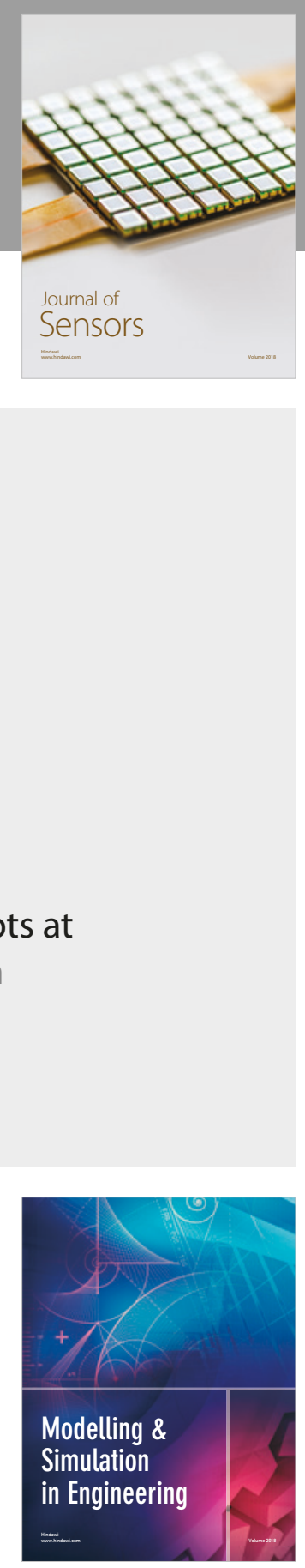

\section{Advances \\ Multimedia}
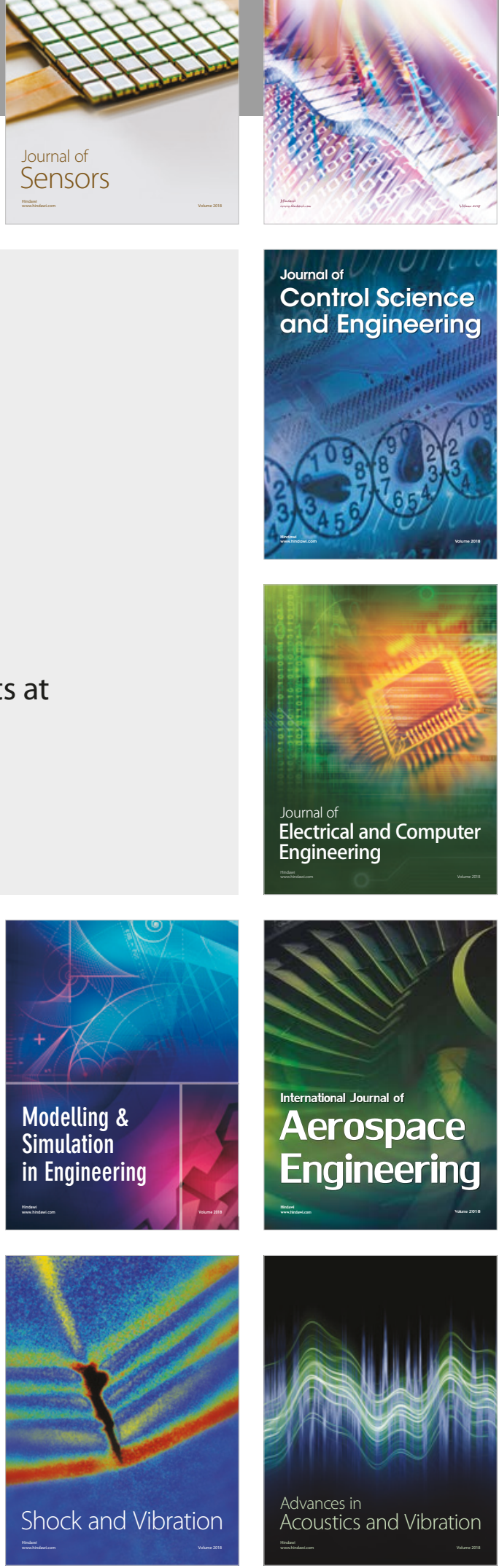